\title{
The role of language learning strategies (LLS) and the effect of different individuals in learning target or second language
}

\author{
Areen Ahmed Muhammed Abdulla \\ University of Sulaimani, School of Education, Chamchamal, English Department, Sulaimaniyah, Iraq \\ Email address: \\ hibalboa@yahoo.com
}

To cite this article:

Areen Ahmed Muhammed Abdulla. The Role of Language Learning Strategies (LLS) and the Effect of Different Individuals in Learning Target or Second Language. International Journal of Language and Linguistics. Vol. 2, No. 3, 2014, pp. 197-202.

doi: $10.11648 /$ j.ijll.20140203.19

\begin{abstract}
Recently, the result of previous studies on the issue of acquiring target language, using different strategies, based on the different individuals inspired many scholars and linguists; and has mushroomed over the last decade since some very valuable studies have been conducted. Additionally, achieving foreign or second language, unlike mother tongue, is very difficult and needs different techniques to be taken in to consideration for a better result. In this regard, the present article aspires at accenting the importance of language learning strategies and highlights the consequence of different learners in achieving target language. It summarizes the concept by giving a brief definition from different point of views; in which first it was believed that it belonged to behaviourist theories, but later it was combined to psychology of different individuals. Later, in another section, various types of strategies were outlined that was proposed by several researchers. Moreover, whether to teach less successful learners successful LLS or teach various types of strategies to every kind of learners were also discussed by different writers ' point of views on choosing an appropriate strategy for a particular student. Finally, each of motivation, self-efficiency, proficiency level, meta-cognitive awareness, gender differences, learning style, types of strategy training and anxiety have been discussed on teaching LLS. Furthermore, some types of activities were given to make easier for individuals to practice their target/second language and acquire the assigned language easily.
\end{abstract}

Keywords: Language Learning Strategies, Target Language, Different Individuals, Strategies Based Instruction, Language Use Strategies

\section{Introduction}

Recently, a prominent shift has been made in the field of Language Learning Strategies (LLS) over the few years and more emphasis was put on learner and learning rather than on teacher and teaching. Moreover, the aim of the paper is to encourage students to learn LLS and adopt some to learn Target Language (TL) faster and effectively. Furthermore, help the learners to use them in different time of their learning stage and life. Additionally, the paper will answer some questions which are ambiguous to the learner, such as: What are those arguments about the strong and weak points of teaching LLS?, How can those strategies be taught effectively? and Whether individual difference factors have indirect role on learning those strategies or not?

The paper starts with a brief introduction of LLS and classifies them according to different scholars` idea. Then it will discuss some pros and cons of them in general which proposed by several writers. Finally, it will mention the proposed ways of teaching LLS and giving some activities as an example. A brief conclusion will finish the paper.

\section{Definitions of the Concept}

As it has believed that, in the field of learning a gradual, but influence, movement has been made. However, the pressure on learners, especially for non-native learners, and less stress on teachers have increased. As a result, the LLS were considered as a crucial product in the field of language learning. The concept of strategy derived from the Greek term (strategia), which will help learners to learn TL easier and able to transform ideas to new contexts. (Oxford, 1990).

In the $1960 \mathrm{~s} / 70 \mathrm{~s}$ LLS were taken as the psychological 
phenomenon; as the idea came with the birth of behaviourist theories, and it was believed that learning a foreign language (FL) will depend on the psychology of different individuals. As Mayer (1988) said that different individual behaviours will influence the way of processing the information. However, through the development of education and learning Canale and Swain (1980) considered Language Strategies (LS) as the component of communicative competence. Latterly, Bachman (1990) developed the idea and described it as linguistic competence. Additionally, strategies are defined as the facilitators that are selected by learners. They will help the early learners comprehend unfamiliar language tasks. As Rubin (1987) described the strategies as a contribution of the language system development and has an impact on learners` learning. Moreover, a study by O`Malley and Chamot (1990) explained the term as a special thought which learners are using to understand new information. Furthermore, Robin (1999) and Schmitt (2002) defined LLS as the conscious and semi-conscious conception of the learners with the explicit aims to develop the comprehensibility of the TL. Through different period of time different scholars and linguists explained and illustrated the term based on their understanding. But, all are talking around the same nucleus idea.

\subsection{Classifications of $L L S$}

The classifications of LLS may vary from one to another researcher. In this section different scholars`categorisation will be shown and each will be explained briefly. Likewise, O’Malley (1985), Rubin (1987), Cohen et al. (1996) and Haung (2003) identified four strategies, which are cognitive, meta-cognitive, social and affective. Usually these strategies will help learners expose to the TL by interacting and practicing, as each is described below:

Firstly, Cognitive strategy deals with recalling information and use background knowledge to learn and tackle TL. Secondly, Meta-cognitive strategy deals with planning and evaluation; it helps learners to monitor their learning process. Thirdly, Social strategy will be used to interact and communicate. And finally, Affective (Communicative) strategy regulates learners ' motivation and attitude to reduce stress and increase self-encouragement.

Additionally, Oxford (1990) and Ehrman et al. (2003) developed the strategies and added some others points as shown below:

- DIRECT STRATEGIES
O I. Memory
- II. Cognitive
○ III. Compensation strategies

- INDIRECT STRATEGIES
- I. Meta-cognitive Strategies
- II. Affective Strategies
- III. Social Strategies

In addition, Stern (1992) cited in Hismanoglu (2000) classified LLS as:

- Management and Planning Strategies.
- Cognitive Strategies.

- Communicative-Experiential Strategies.

- Interpersonal Strategies.

- Affective Strategies.

Moreover, Schmitt (2002), and Richards and Renandya (2002) identified two more strategies. Firstly, they mentioned the strategy which is identified by different skills; they divided into receptive and productive skills. Receptive skill includes listening and reading and productive includes speaking and writing. However, there are different skills for vocabulary and translation. Secondly, they mentioned another strategy which is called self-motivating strategy. This strategy solely depends on the learners themselves and they learn the language without the assessment of the teachers.

\section{Critiques and Benefits of Teaching These Strategies}

The debate between scholars still are continuous, whether to teach less successful learners successful LLS or teach various types of strategies to every kinds of learners. A successful learner according to Rubin (1975) is an accurate guesser who has sense to communicate, uninhabited, willingly accept mistakes to learn and take advantage of practicing/monitoring him/her self. Besides, in their sources, Oxford (1990), and Hsiao and Oxford (2002) contributed some benefits of LLS. They believed that using different portions of strategies in the classes, especially to learn a target language, will help learners to focus more on the main goal and students should be learned to be self-directed; consequently, students will depend more on their knowledge. However, teachers should work as facilitators, helpers, guidance and advisors; rather than just knowledge giver. Furthermore, instructors should help learners to use language practically. Additionally, Hsiao and Oxford stated that different individuals may learn different language strategies. As a result, this will support learners both directly and indirectly to learn TL, because the strategies are flexible and can be learned easily. Also, the scholars believed that these strategies will deal with both conscious and semi-conscious learners to increase their confidence in using languages. Likewise, the strategies can be used for all tasks and the guidance will help students to use the reliable strategy in the new context. Finally they declared that these strategies will help the learners to understand and recall the information. For example, memory and cognitive strategy will increase the ability of grammatical accuracy. Moreover, social strategy will help social interaction and communication.

However, Cohen (1998) illustrated that these strategies have a better affect in short term use only. He made a study on a group of teachers from different nationalities at the University of Minnesota entitled "strategies-based foreign language learning". The main focus was on the creation of strategy-based instruction materials by the teachers 
themselves. He concluded five problematic issues in LLS in general and Strategies Based Instruction (SBI) in specific:

1. Using the term-strategy: Many sub-categorizations have been made in LS, while still the term has not been separated from techniques, tactics and sub-strategies.

2. Conscious use of strategies: In most cases learners cannot preserve the strategy explicitly and the ideas cannot be transferable to the new contexts. As a result, the learners need the teachers as a source of guidance all the time.

3. Classifying the strategies: Oxford's classification is designated for different purposes that used in explicit situation. However, some test like speaking task needs elicit training. It will be hard to maintain enough information through those strategies.

4. The broader concept of strategies competence: It will be difficult for the learners to determine which strategy they need to choose in the non-native task.

5. Linking strategies to learning styles and other personality-related variables: Students cannot be sub-divided according to their demographic and other categories. Otherwise, it will be hard to identify the usefulness of different strategies on different personal variables.

Nevertheless, Dornyei and Skehan (2003) cited in Cohen and Macaro (2007) mentioned some problematic issues in LLS. Firstly, it is hard to illustrate the differences between engaging in an ordinary learning activity and a strategic learning activity. Secondly, the use of strategy inventory has a serious fault in its arrangement (system).

Other arguments have been made on relating those strategies to the cognitive behaviours. Actually, the use of these strategies will depend on different psychological behaviours and it will be hard to identify the exact strategy to learn TL as Ehrman et al. (2003) said that the LS can be taught neutrally, neither good nor bad, under different contexts. The strategies will depend on the L2 task, proficiency level and the linkage of the strategies to each other. The usefulness of these strategies will depend on the different individuals. Moreover, it is not easy to discover those strategies that learners are using unless you know about their psychological mechanism of different individuals. As Cohen and Macaro (2007) quoted from the work of Seliger (1983:180), as he illustrated the lack of ability to know what is happening in the learners' mind. And, the lack of available and accurate research on meta-language.

In comparison, some benefits of LLS have been determined. They have a significance role in altering reliability and focus of learning from teachers to the shoulder of students. As Grenfell and Harris (1999) cited in Cohen and Macaro (2007), ways of teaching and learning procedures should be balanced or coherent. Whilst, the problem is that to what extent these strategies will be applicable to all and are innate in their mind.
However, the debate is still continuous that observing different strategies not only depend on the proficiency of the learners, but the environment has a crucial role to indicate which strategy suit which types of learners. According to the educational background and personal experience the strategies can be taught effectively when teachers keep themselves away from the personal profile of the learners and move to individual differences. Additionally, teachers should depend on the quality of the use of these strategies rather than quantity. If these two ideas came in to consideration, a better result could be found. As a result, the learners could be able to practice those strategies that they learned practically. Through his study, Henmer-stanchina (1982) cited in Haung (2003), he carried out a study on a university level and through the result he concluded that each strategy can be taught separately and successfully and will have a foreseeable effect on the improvement of students ' learning. In another Source, O`malley et al. (1985) used the four main strategies on both Asian and Hispanic ESL learners' both listening and speaking skills to examine the effectiveness of the strategies. The result concluded that the strategies worked with speaking and not listening. However, it indicated that the Asian students preferred own established LLS. Furthermore, Nunan (1997) made an experiment on students ' writing and speaking skills through the strategies. The main reason of the study was to find out the effect of these strategies on students ' motivation. The result showed that they can use the strategies in the new context. Additionally, Chamot and Kupper (1989) collected data on high school students who were taught listening and speaking. The result proved that the success of LLS depend on the interest of teachers and given instruction on one hand and ability to aid students to use those strategies on another hand. By contrast, Haung (2003) clarified some problems that still exist, such as: some teachers conduct the strategies, they know how to teach them theoretically, but unable to use them practically. On the other hand, the time to spend on teaching LLS is very short in some places and learners unable to use them practically. As a result, the strategy is only a system to learn language rather than a tool to use. Finally, individual differences, personal style and different ethnic background have been neglected in some places. Through different studies each writer believes in a way which is different from others, while they all agreed on the concept to use these strategies, especially to learn a target language, and defiantly the use of different strategies may change among different individuals and education backgrounds.

\section{Proposed Ways of Teaching LLS}

Individual difference factors, such as: motivation, self-efficiency, proficiency level, meta-cognitive awareness, gender differences, learning style, types of strategy training and anxiety have indirect roles on teaching LLS. However, each writer has his/her own contributions. Ways of teaching 
will differ from one to another writer, Wenden and Rubin (1987) suggested a way which the learner will not work with the teacher in a traditional way; in contrast, s/he will work with the teacher in the sense of individual non-directive interviews. Then they will decide and discuss the different types of LS. After that the learner will practice the strategies. It is believed that, such way of teaching will help the learner to grab the process and use the strategies in the real-life. Additionally, teachers should give instructions about the materials. Then, students use their ideas to precede the strategy. Finally, the learner should be asked to select appropriate strategy for the material. This will help the student to not under estimate his/her proficiency level and academic background.

As it has been identified, according to the personal background, inventory is one of the ways to teach LLS. Whilst, it is not accessible for all socio-cultural areas, therefore it will be less valid, because the use of the strategies will be different from one to other learning circumstances. Moreover, these strategies will depend on the situation which the learners find themselves in and level of awareness has an indirect influence. Furthermore, more claims have been made on the transferability of those strategies from one to another learner. Moreover, O`malley and Chamot (1990) addressed some ways to teach LLS:

i. Separate vs. integrated instruction: O'malley and Chamot (1990: 152) said"An unresolved issue in instruction in learning strategies is whether instruction should focus only on learning strategy instruction or should be integrated with classroom instruction in the language or content subject."

The learners will learn better if their only focus will be on developing strategic processing skills rather than learn the content at the same time. One of those ways to teach is CACL program (Computer-Assisted Cooperative Learning) for separate instruction. This way will help the reading comprehension of the students through computer programs and will guide them for planning, monitoring and concentrating. However, integrated one deals with the context based and it is preferred to the separate instruction in its effectiveness. This type will help learners to transfer those in to new contexts. As Dansereau (1985) claimed that, it will not be easy for the learners to adapt all those strategies which they have learned in computer based system (CACL) to specific contexts, because the way of teaching in CACL is designed for a specific type of scientific text.

ii. Direct vs. Embedded instruction: In direct instruction, learners are guided to learn the purpose of strategies. However, in embedded, the learners are asked to practice the strategies in different contexts to inspire them to use the strategies without giving them the reason of teaching the materials. By contrast, that idea has been developed and nowadays they have been informed about the purpose and importance of the study and known as meta-cognitive component. This way of teaching helped learners to comprehend reading texts easily and enable them to grab information much quicker. Additionally, Palincsar and Brown (1984), Derry and Murphy (1986), and Winograd and Hare (1988) preferred direct to embedded, because those learners who are not aware of the strategy which they are using, they cannot use them independently and it will give them less opportunity to become autonomous learners.

The options to provide LLS training may differ from one educational setting to another, the level of explicitness, learners` awareness and transferability of the strategies, as Cohen (1998) described them as:

a. General study-skill courses: It will help different individuals to learn TL easily through diagnosing learning preferences. It will help students to participate and introduce their ideas.

b. Awareness training:

i. lectures and discussion: It is known as conscious rising, because it deals with classroom interaction. It will help the learners to understand each type of strategy.

ii. Strategy workshop: Applying strategies in a workshop to drill the information.

c. Peer tutoring: Direct language exchange will help the learners to use those strategies in a natural environment.

d. Strategies inserted into language text books: Applying the strategies on the classroom textbook, it will teach the learners how to use the strategies in the new contexts.

e. Videotaped mini-courses: Videoing the learners will break their shyness and increase their confident to use the strategies properly.

f. Strategies-based instruction (SBI): It is students-centred class and helps them to include both implicit and explicit integration and use the strategies fluently.

Furthermore, Ehrman et al. (2003) proposed some ways to teach the strategies which are: Testing the internal connection with the new materials. Doing effective survey in the class will increase the students' maintenance. Moreover, another way is interview, which will increase learners` extrinsic level beside motivation. Additionally, Oxford and Nyikos (1989) made a study on 1200 undergraduate English students (mixed genders) who were studied five different foreign language. The study used SILL (Strategy Instructions Language Learning). The writers admitted that the use of appropriate strategy will help the proficiency level. In addition, gender differences are considered as another option to apply those strategies. Male gender prefers Model strategy, while female prefers elicitation strategies due to male/female dominant orientation society. While, According to Nunan (1997), and Cohen and Macro (2007) LLS can be taught through predicting, self-evaluating, memorizing, confirming, inductive vs. deductive learning, predicting interviews, observations and group discussions. Hence, they proposed 
two ways to teach LLS, which are:

a. CALLA (The Cognitive Academic Language Learning Approach): This will encourage teachers to teach different strategies in the class.

b. SBI: This will give learners responsibility and use the strategies independently, such as:

I. Raise the cognitive awareness of the learners.

II. Teachers will act as guidance and students as self-directed.

III. Develop the improvement of students in using the strategies.

IV.Self-evaluation and apply the strategies on new tasks.

\subsection{Activities}

Identifying the place of strategies is one of the activities. Learners should predict both the learning strategies and acquisition of the strategies to form a continuum as follow:

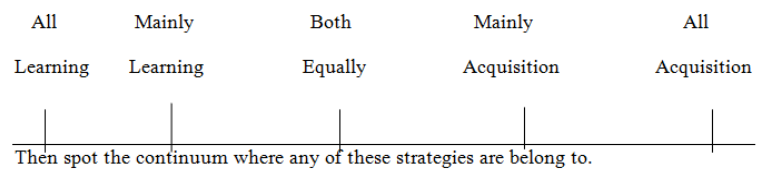

(Oxford, 1990)

Furthermore, another exercise deals with the use of the strategies as a game. Students should participate in small groups. Later, teacher should ask them to determine which language activity belongs to a specific strategy. The greatest number of language activity should be matched to the strategy in the limited time. The activity will be in this form:

i. Introduction: Teacher should give a brief introduction about the game.

ii. Practice: Before the group division, teacher should read the language activities' description. Later, ask them for a brief recalling, enable everyone take a part in the game.

iii. Play: divide students to small groups and let the students to use their information to find out the answer.

iv. Explanation of strategy choice and determination of scores: Ask each group to post their work in front of the class. The spokes-person of the group explains the reason behind their choices. Usually the strategies can be explained within one sentence, but the participants need more to express their ideas. However, to be fairer another group who come after should say new ideas rather than repeated information.

v. The teacher should leave some times at the end to discuss what they have learned and finally, how to use them naturally. (Oxford, 1990)

\section{Conclusion}

The use of the strategies will separate more effective learners from less. This will help to develop the students proficiency. Moreover, it will help students to be more critical, self-reliance and use TL more freely. The paper indicated some ways to teach LLS and bring some arguments of the different researchers on teaching them. However, still there are some problems and confusion to solve and overcome. Finally, LLS are tactics which help EFL/ESL learners to practice the TL through specific strategies. In the matter of fact age, proficiency level, gender, life-experience and learning style are considered as indirect factors on the role of LLS.

\section{References}

[1] Canale, M. and Swain, M. (1980) Theoretical Bases of Communicative Approach to Language Teaching and Testing, Applied Linguistics, 1 (1), 1-47.

[2] Chamot, A. and Kupper, L. (1989) Learning Strategies in Foreign Language Instruction, Foreign Language Annals, 22 (1), 13-22.

[3] Hismanoglu, M. (2000) Language Learning Strategies in Foreign Language Learning and Teaching, The Internet Tesl Journal, 6 (8), 1-9.

[4] Bachman, L.F. (1990) Fundamental Consideration in Language Testing. Oxford: Oxford University Press.

[5] Canale, M. and Swain, M. (1980) Theoretical Bases of Communicative Approach to Language Teaching and Testing, Applied Linguistics, 1 (1), 1-47.

[6] Chamot, A. (2005) Language Learning Strategy Instruction: Current Issues and Research, Annual Review of Applied Linguistics, 25, 112-130.

[7] Chamot, A. and Kupper, L. (1989) Learning Strategies in Foreign Language Instruction, Foreign Language Annals, 22 (1), 13-22.

[8] Cohen, A. D. (1998) Strategies in Learning and Using a Second Language. London: Longman.

[9] Cohen, A. and Macaro, E. (Eds.) (2007) Language Learner Strategies: 30 Years of Research and Practice. Oxford: Oxford University Press.

[10] Cohen, A., Weaver, S. and Li, T. (1996) The Impact of Strategies-Based Instruction on Speaking a Foreign Language. Centre for Advanced Research on Language Acquisition, University Of Minnesota.

[11] Dansereau, D. (1985) Learning Strategy Research. In J.W. Segal, S.F.Chipman, and R. Glaser (Eds.). Thinking and Learning Skills. (Vol. 1). Hillsdale, NJ: Erlbaum. 209-239.

[12] Derry, S. J. and Murphy, D. A. (1986) Designing Systems that Train Learning Ability: From Theory to Practice, Review of Educational Research, 56 (1), 1-39.

[13] Ehrman, M., Leaver, B. and Oxford, R. (2003) A Brief Overview of Individual Differences in Second Language Learning, System, 31, 313-330.

[14] Hismanoglu, M. (2000) Language Learning Strategies in Foreign Language Learning and Teaching, The Internet Tesl Journal, 6 (8), 1-9. 
[15] Hsiao, T. and Oxford, R. (2002) Comparing Theories of Language Learning Strategies: A Confirmatory Factor Analysis, The Modern Language Journal, 86 (3), 368-383.

[16] Huang, H. (2003) Can Learning Strategies be Taught in Classroom?, General Education Centre, 21(1), 417-424.

[17] Jamieson, J. and Chapelle, C. (1987) Working Styles On Computers As Evidence Of Second Language Learning Strategies, Language Learning, 37(4), 523-544.

[18] Mayer, R. (1988) Learning Strategies: An Overview. In Weinstein, C., E. Goetz, and P. Alexander (Eds.), Learning and Study Strategies: Issues in Assessment, Instruction, and Evaluation (pp. 11-22). New York: Academic Press.

[19] Nunan, D. (1997) Strategy Training in the Language Classroom: An Empirical Investigation, Relc Journal, 28 (2), 56-81.

[20] O'malley, J.M., and Chamot, A. V. (1990) Learning Strategies in Second Language Acquisition. Cambridge: Cambridge University Press.

[21] O'malley, M. J., Chamot, U. A., Stewner-Manzanares, G., Russo, R. and Kupper, L. (1985) Learning Strategy Applications with Students of English as a Second Language, Tesol Quarterly, 19 (3), 557-584.

[22] Oxford, R. (1990) Language Learning Strategies: What Every Teacher Should Know. Alabama: Heinle \& Heinle Publishers.

[23] Oxford, R. and Nyikos, M. (1989) Variables Affecting Choice of Language Learning Strategies by University Students, the Modern Language Journal, 73 (3), 291-300.

[24] Palincsar, A.S. and Brown, A. L. (1984) Reciprocal Teaching of Comprehension-Fostering and Comprehension-Monitoring Activities, Cognition and Instruction, 1 (2), 117-175.

[25] Richards, J. C. and Renandya, W. A. (2002) Methodology in Language Teaching: An Anthology of Current Practice. New York: Cambridge University Press.

[26] Riding, R. and Rayner, S. (1998) Cognitive Styles and Learning Strategies: Understanding Style Differences in Learning and Behaviour. London: David Fulton Publisher.

[27] Rubin, J. (1975) What the "Good Language Learner" Can Teach Us, Tesol Quarterly, 9 (1), 41-45.

[28] Rubin, J. (1987). Learner Strategies: Theoretical Assumptions, Research History and Typology. In A. Wenden and J. Rubin (Eds.), Learner Strategies and Language Learning (P.P 15-29). Englewood Cliffs, NJ: Prentice Hall.

[29] Schmitt, N. (Ed.) (2002) Introduction to Applied Linguistics. London: Arnold.

[30] Wenden, A. and Joan R. (Eds.) (1987) Learner Strategies in Language Learning. Englewood Cliffs, NJ: Prentice Hall International.

[31] Wigfield, A. and Eccles, J. (1992) The Development of Achievement Task Values: A Theoretical Analysis, Developmental Review, 12, 265-310.

[32] Winograd, P. and Hare, C.V. (1988) Direct Instruction of Reading Comprehension Strategies: The Nature of Teacher Explanation. In C.E. Weinstein, E.T. Goetz, and P. A. Alexander (Eds.), Learning and Study Strategies: Issuer in Assessment, Instruction and Evaluation (P.P 121-139). New York: Academic Press. 